\title{
Acute Eosinophilic Pneumonia with Respiratory Failure Induced by Synthetic Cannabinoid Inhalation
}

\author{
Nesrin Öcal ${ }^{1}$, Deniz Doğan ${ }^{1}$, Ali Fuat Çiçek ${ }^{2}$, Orhan Yücel ${ }^{1}$, Ergun Tozkoparan ${ }^{1}$ \\ 'Department of Chest Diseases, Gülhane Training and Research Hospital, Ankara, Turkey \\ ${ }^{2}$ Department of Pathology, Gülhane Training and Research Hospital, Ankara, Turkey
}

Background: In recent days, synthetic cannabinoid derivatives have become life threatening for young people. Here, we want to share a case of acute eosinophilic pneumonia triggered by inhalation of synthetic cannabinoid, new side effects of which are being detected day by day.

Case Report: A 21-year-old male, who had no history of pulmonary diseases, was admitted to the clinic with shortness of breath. His oxygen saturation was measured as $85-86 \%$ in room air. Common irregular ground-glass opacities were observed in thorax radiology. His peripheral blood eosino- phil count was 1100 cell $/ \mathrm{mm}^{3}$ with a leukocyte differential of $12 \%$. Sputum eosinophilia was also observed. The patient was diagnosed with acute eosinophilic pneumonia in terms of current clinical, radiological and laboratory findings. Rapid remission was achieved with corticosteroid therapy.

Conclusion: This is the first reported case of acute eosinophilic pneumonia induced by synthetic cannabinoid inhalation.

Keywords: Acute eosinophilic pneumonia, sputum eosinophilia, synthetic cannabinoid
Acute eosinophilic pneumonia (AEP) is a rare eosinophilic lung disease diagnosed based on the combination of acute fever, hypoxemia, radiological opacities, broncho-alveolar lavage (BAL) fluid consisting of $>25 \%$ eosinophils, absence of parasitic, fungal or other infections, which may lead to eosinophilia, prompt and complete response to corticosteroid treatment, and the lack of a relapse after the discontinuation of steroid therapy $(1,2)$.

Various drugs, types of cigarette smoke, toxic gases and narcotics have been implicated in the etiology of AEP (2). AEP can be observed in all age groups with an average of 29 years and in two genders equally. Given that the cases reported throughout the Europe, United States and Japan, it is difficult to claim that there is a geographical endemic nature of AEP $(1,2)$.

In this paper, we present an AEP case triggered by the inhalation of synthetic cannabinoid. To best of our knowledge this is the first reported case of AEP due to synthetic cannabinoid inhalation.

\section{CASE PRESENTATION}

A 21-year-old male with shortness of breath was referred to our clinic. He reported that dyspnea began about a week ago and increased immediately in the last 1-2 days. The patient had no history of any pulmonary diseases. In physical examination; fever was $38.8^{\circ} \mathrm{C}, \mathrm{SpO}_{2}$ (at room air) was $85-86 \%$, pulse was 105 beats $/ \mathrm{min}$. and arterial blood pressure was measured as $125 / 75 \mathrm{mmHg}$. In oscultation, coarse breath sounds and sporadic crackles were heard in both hemithorax. Because of the generalized reticular radio-opacities in both middle and lower zones, which were more pronounced in the lower zones and paracardiac areas on the chest radiography, high resolution computed tomography (HRCT) was performed (Figure 1). In thorax HRCT irregular areas of ground glass opacities were observed evidently in the central part of the lower lobes (Figure 2). The complete blood count showed that WBC count was 9100 cells/ $\mu \mathrm{L}$ with $12 \%$ eosinophils (total eosinophil count of 1100 cells $/ \mu \mathrm{L}$ ). The other total blood count values, sedimentation, CRP and blood

This case has been presented at the $36^{\text {th }}$ National Congress of Turkish Respiration Society, 14-15 October 2014, İmir, Turkey.

Address for Correspondence: Dr.Nesrin Öcal, Department of Chest Diseases, Gülhane Training and Research Hospital, Ankara, Turkey

Phone: +905055044715_e-mail: nesrinbaygin@yahoo.com

Received: 18 February $2015 \quad$ Accepted: 4 December $2015 \quad$ DOI: 10.5152/balkanmedj.2016.151145

Available at www.balkanmedicaljournal.org

Cite this article as:

Öcal N, Doğan D, Çiçek AF, Yücel O, Tozkoparan E. Acute eosinophilic pneumonia with respiratory failure induced by synthetic cannabinoid inhalation. Balkan Med

J 2016;33:688-90. 

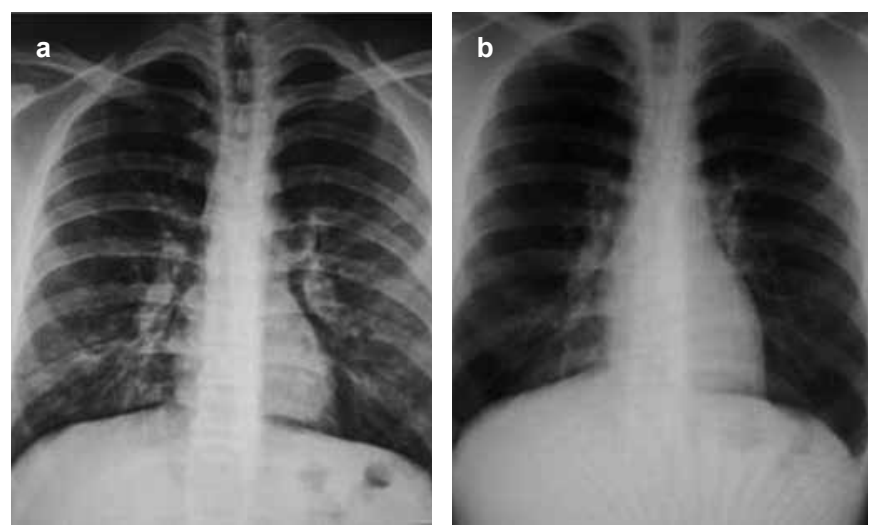

FIG. 1. a,b. Chest X-ray of the patient. Generalized reticular radioopacities in the middle and lower zones were observed in the chest $\mathrm{X}$-ray obtained on the first day (a). Chest X-ray at the end of the first week of the prednisolone treatment, fully clean (b)

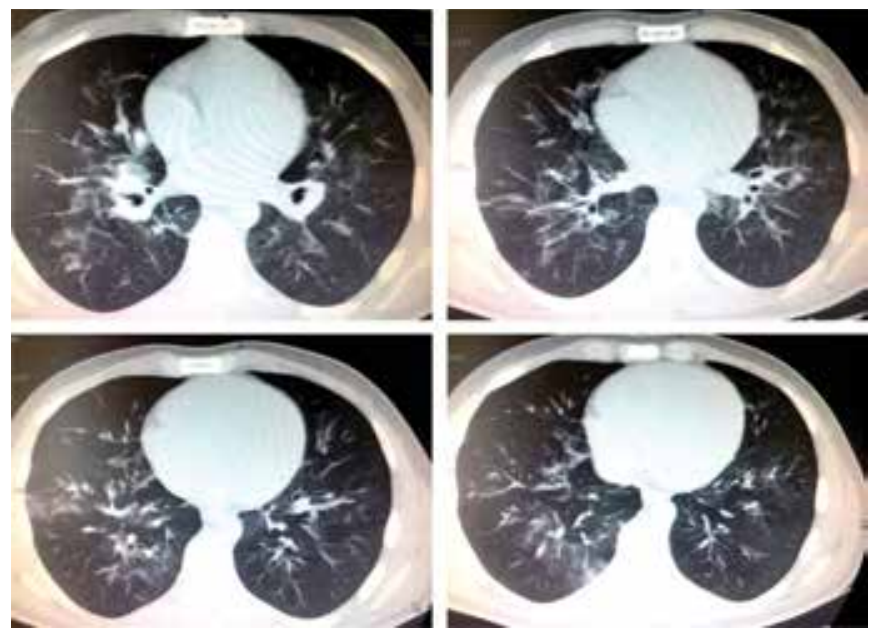

FIG. 2. Thorax HRCT images, irregular ground glass opacities were observed. HRTC:high resolution computed tomography

chemistry values were within normal limits. The peripheral eosinophilia $(>500 \mathrm{cell} / \mathrm{s} / \mathrm{L})$ was a striking finding. Arterial blood gas results were $\mathrm{pH}: 7.39, \mathrm{PCO}_{2}: 30.3, \mathrm{PO}_{2}: 53.4, \mathrm{SaO} 2: 88.2 \%$. In order to examine possible underlying etiologies of eosinophilic lung diseases, the patient's history was deepened and history of drug or substance abuse were also questioned persistently. Whereupon, the patient told that he was a substance abuser. He had been using cannabis and heroin for a long time and had started to inhale synthetic cannabinoid over the last month. He had also increased the frequency of inhalation during the last week.

The patient was hospitalized under close clinical follow-up and oxygen support. Before the initiation of empiric antibiotic treatment, possible etiological causes of eosinophilic lung diseases such as parasitic-fungal infections, allergic bronchopulmonary aspergillosis (ABPA), hematologic and rheumatologic diseases were excluded by blood and sputum cultures, microbiological investigations, immunological tests and a peripheral blood smear. In order to receive a BAL sample, diagnostic bronchoscopy procedure was proposed to the patient but he did not accept the process. Whereupon, sputum cytology was taken to investigate the possible pulmonary eosinophilia status. The most significant laboratory finding was sputum eosinophilia of $12.5 \%$.

The patient was diagnosed with AEP due to these clinical, radiological and laboratory findings, and $80 \mathrm{mg} /$ day parenteral prednisolone was added to his existing treatment regimen. On the third day of the prednisolone treatment regimen, significant clinical and radiological improvement was observed. Chest X-ray findings, peripheral blood and sputum eosinophil counts and oxygen saturation in room air were observed to be normal by the end of the first week of the prednisolone treatment (Figure 1). Thereon; the antibiotic treatment was ended, steroids were tapered to $60 \mathrm{mg} /$ day and maintenance treatment was planned. The prednisolone treatment was tapered in 6 weeks. Patient consent form was approved for this case report.

\section{DISCUSSION}

Although AEP is a rare clinical entity, it is an important pulmonary pathology that can prove fatal unless appropriate treatment is provided. There are not many clinical studies on this subject in the literature and most of the publications are in the form of case reports $(1,2)$. Considering that, drug inhalation frequency has increased in recent years and also AEP cases due to substance inhalation such as cannabis and heroin came into prominence in the present literature; pulmonary effects of the drugs became more important in clinical respect $(1,3)$. On the other hand, we have not encountered an AEP case induced by synthetic cannabinoids, which have recently gained in popularity.

Synthetic cannabinoids are harmful drugs. Use has become widespread because they can be obtained illegally. In different countries, they have got many street names such as 'bonzai', 'Spice', 'K2', 'Agent Orange', 'Atomic Bomb' and 'Jamaican Gold Extreme'. Synthetic cannabinoids are made by impregnating the completely synthetic several drug chemicals to dried leaves of some plants. Because of their cheap prices, easy availability and strong effects, they have become popular among addicts. Addicts use these drugs by oral, inhaled or sniffing ways (3). In the present case, the patient inhaled synthetic cannabinoid by rolling his own cigarettes. In previous cases, clinical case reports of patients who were acutely intoxicated after the consumption of synthetic cannabinoids describe a variety of somatic and neuropsychiatric effects. However, this is the first case report that emphasizes AEP among the other side effects of synthetic cannabinoids $(4,5)$. 
Although peripheral eosinophilia is often an unexpected finding in AEP, the hypersegmentation of blood eosinophil nuclei and initial peripheral eosinophilia have also been reported to be a clue to the diagnosis and the prognosis of AEP in clinical practice $(1,6)$. Peripheral eosinophilia has been demonstrated in many AEP cases previously, a detailed statistical data on this issue has not been reported probably because of the limited number of AEP cases $(6,7)$. In our case, peripheral eosinophilia was guiding us to recognize AEP.

Broncho-alveolar lavage eosinophilia is observed in over $25 \%$ of AEP cases (2). However, the patient may refuse to undergo bronchoscopy. In such cases, abstaining stay in the diagnosis of AEP due to BAL eosinophilia deficiency, may delay the necessary steroid treatment and even lead the clinicians to delayed diagnosis or misdiagnosis. From this point of view, sputum eosinophilia, a commonly used marker in the diagnosis and prognosis of many eosinophilic lung diseases, is sufficient for the diagnosis of AEP and can be used instead of BAL eosinophilia (8). It is well known that eosinophils are typically absent in sputum samples of healthy subjects. The upper normal limit of sputum eosinophils in adults and children is $2.5 \%$ or less of cells. In the literature sputum eosinophil counts $>2.5-4 \%$ was described as sputum eosinophilia. Many clinical trials have showed that sputum eosinophilia is a good inflammatory marker for eosinophilic lung diseases. Sputum analysis provides a non-invasive method of examining the airway secretions of subjects with eosinophilic lung diseases such as AEP, chronic eosinophilic pneumonia, Loeffler's syndrome and tropical pulmonary eosinophilia $(9,10)$.

Here we present the first reported case of AEP induced by synthetic cannabinoid inhalation. The recently increased and widespread use of these synthetic drugs suggests that many more AEP cases may be encountered in the future. We hope this case will stimulate additional research.

\section{Ethics Committee Approval: N/A.}

Informed Consent: Written informed consent was obtained from the patients who participated in this study.

Peer-review: Externally peer-reviewed.
Author contributions: Concept - N.O.; Design - D.D.; Supervision - E.T.; Data Collection and/or Processing - D.D., A.F.C., O.Y.; Analysis and/or Interpretation - N.O., D.D., E.T.; Literature Search - N.O., D.D., A.F.C.; Writing - N.O., D.D., A.F.C., E.T.; Critical Reviews - E.T., N.O., D.D., O.Y., A.F.C.

Conflict of Interest: No conflict of interest was declared by the authors.

Financial Disclosure: The authors declared that this study has received no financial support.

\section{REFERENCES}

1. King MA, Pope-Harman AL, Allen JN, Christoforidis GA, Christoforidis AJ. Acute eosinophilic pneumonia: radiologic and clinical features. Radiology 1997;203:715-9. [CrossRef]

2. Rom WN, Weiden M, Garcia R, Yie TA, Vathesatogkit P, Tse $\mathrm{DB}$, et al. Acute eosinophilic pneumonia in a New York City firefighter exposed to World Trade Center dust. Am J Respir Crit Care Med 2002;166:797-800. [CrossRef]

3. Uchiyama N, Kawamura M, Kikura-Hanajiri R, Goda Y. A new class of designer drug and 12 synthetic cannabinoids detected in illegal products. Forensic Sci Int 2013;227:21-32. [CrossRef]

4. Forrester MB, Kleinschmidt K, Schwarz E, Young A. Synthetic cannabinoid exposures reported to Texas poison centers. $J$ Addict Dis 2011;30:351-8. [CrossRef]

5. Hermanns-Clausen M, Kneisel S, Szabo B, Auwärter V. Acute toxicitydue to the confirmed consumption of synthetic cannabinoids: Clinical and laboratory findings. Addiction 2013;108:534-44. [CrossRef]

6. Wechsler ME. Pulmonary eosinophilic syndromes. Immunol Allergy Clin North Am 2007;27:477-92. [CrossRef]

7. Jhun BW, Kim SJ, Kim K, Lee JE. Clinical implications of initial peripheral eosinophilia in acute eosinophilic pneumonia. Respirology 2014;19:1059-65. [CrossRef]

8. Hendrick DJ, Spicket GP. Eosinophilic pneumonia. In: Warrell DA, Cox TM, Firth JD, Benz EJ, editors. Oxford Textbook of Medicine. Oxford: Oxford University Press; 2003:1482-3.

9. Patterson C, Coleman M, editors. Revision Notes for the Respiratory Medicine Specialty Certificate Examination. Oxford: Oxford University Press; 2012:67-8.

10. Mahatma M, Haponik EF, Nelson S, Lopez A, Summer WR. Phenytoin-induced acute respiratory failure with pulmonary eosinophilia. Am J Med 1989;87:93-4. [CrossRef] 